\title{
Guerra Civil i narrativa juvenil catalana: testimoni i literatura
}

\author{
Caterina VALRIU \\ Departament de Filologia Catalana i Lingüística General \\ Universitat de les Illes Balears \\ c.valriu@uib.cat
}

\begin{abstract}
RESUM
En la narrativa juvenil catalana la novel-la de tema històric ha estat sempre molt conreada, però fins a finals del s. XX el tema de la Guerra Civil va ser poc tractat. En canvi, en aquests últims vint anys molts d'autors han fet de la guerra i la postguerra el tema central de les seves obres. L'article analitza aquesta producció tot revisant la interacció entre realitat i ficció (els anys de guerra, la repressió de la postguerra, l'exili, els camps de concentració, les represàlies, etc.), les tipologies narratives, la ideologia que vehiculen, l'autoria i els paratextos del llibres. Finalment, s'elaboren unes conclusions que posen de relleu el significatiu paper d'aquestes obres en la consolidació de la novel-la juvenil i la visió del conflicte que transmeten, sempre des de l'òptica dels vençuts i a favor de la pau, la llibertat, la democràcia i el respecte a la cultura catalana.
\end{abstract}

Paraules clau: Guerra Civil, República, dictadura, maquis, rojos (d'ideologia republicana), nacionals (d'ideologia feixista)

[Recibido, julio 2012; aprobado, noviembre 2012]

\section{The Spanish Civil War and the Catalan Young Adult Narrative: Testimony And Literature}

\begin{abstract}
The historical novel has been a highly cultivated genre in Catalan Young Adult Literature, but until the end of the 20th century, the topic of the Spanish Civil War was little dealt with. However, during the last twenty years many authors have chosen the Spanish Civil War and postwar period as a central topic of their literary works. The article analyzes this production taking as a starting point the revision of the interaction between reality and fiction ( the war years, the postwar repression, the exile, the concentration camps, the reprisals, the maquis etc. ). It also considers the narrative typologies, the ideology that they convey, the authorship and the paratexts of the books. Finally, the conclusions which are drawn highlight the significant role of these works in the consolidation of the novel for young adults and the vision of the conflict that they transmit, always from the point of view of the defeated and on behalf of peace, freedom, democracy and respect for the Catalan culture.
\end{abstract}

Keywords: Spanish Civil War, Republic, dictatorship, maquis, Reds ( of republican ideology ), nationalists (of fascist ideology) 


\section{Novel·la i història, un joc de complicitats a la literatura juvenil catalana}

Sovint es fa difícil distingir entre les obres que podem anomenar pròpiament novel·les històriques i les d'ambientació històrica. La distinció entre unes i altres hauria de recaure en el pes del factor històric en el context de la narració. Quan l'argument gira entorn del desenvolupament i l'explicació d'un fet històric i aquest és l'eix de la novel·la no hi hauria cap dubte, ens trobem davant una narració històrica. En canvi, quan els esdeveniments històrics són usats com a rerefons per a desenvolupar arguments que posen l'accent en l'aventura, el creixement psicològic dels personatges, els sentiments, etc. i el motiu o context històric pren un paper referencial o secundari, probablement haurem de qualificar aquestes obres com a novel·les d'ambientació històrica. Tanmateix, la distinció entre unes $\mathrm{i}$ altres no és sempre clara, perquè pesar i mesurar en literatura és sempre un exercici difícil $\mathrm{i}$ arriscat.

Des d'aquesta doble perspectiva, volem encetar en aquestes pàgines una reflexió sobre l'ús del tema de la Guerra Civil en la novel-la històrica o d'ambientació històrica en llengua catalana adreçada a un públic juvenil entesa com una part de la tasca de recobrament dels senyals d'identitat catalans després dels anys de silenci i ocultació imposats pel franquisme. Un cop d'ull a les novel·les històriques publicades en català des de la represa dels anys seixanta ${ }^{1}$ ens porta a formular una sèrie d'interrogants.

En primer lloc, quins períodes són novel·lats? Inicialment, podem dir que es novel·len aquells que resulten més atractius pels aspectes positius que comporten vers l'expansió i el desenvolupament històric de Catalunya (els comtes catalans, la figura del rei Jaume I el Conqueridor, els almogàvers, etc.) però aquesta afirmació deixa de ser certa quan es comencen a publicar novel-les que de manera directa o indirecta tracten el tema de la Guerra Civil a Catalunya. També -a les primeres dècades del ressorgiment de la literatura juvenil catalana- es novel-len els períodes que són cabdals per a entendre el per què del desenvolupament de la història del país (la repoblació, el compromís de Casp, la Guerra del Francès o de la Independència) o que tenen un component social i alhora romàntic engrescador per als adolescents (el cas dels pirates i els bandolers al llarg dels segles XVIIXVIII o l'emigració a Amèrica el s. XIX, per exemple). Gairebé fins a finals de la dècada dels noranta la majoria de novel·les històriques juvenils se situaven, doncs, entre el segle XII i el XIX, amb una marcada preferència per l'època medieval. Hi havia períodes molt tractats i altres d'oblidats, com per exemple la romanització, el s. XVIII i -essencialmenttot el s. XX. La història més recent del país -tot i tenir prou ingredients per ser novel·ladano semblava interessar els nostres autors, però aquest fet va canviar radicalment a l'última dècada del s. XX i la primera del s. XXI, quan es publicaren tota una allau de novel-les que tracten de forma directa o indirecta el conflicte de 1936-39 i altres temes que en deriven, com la resistència dels maquis, la repressió de la postguerra, etc. Cal tenir en compte que, pràcticament fins al final del conflicte, gran part de les terres catalanes van ser fidels a la República i contràries a les tropes de Franco, aquest fet i la brutal repressió posterior a tot el que fos català, fan que les novel·les sobre la guerra escrites des de Catalunya siguin la crònica d'una derrota.

En començar a treballar el tractament de la Guerra Civil a la narrativa juvenil catalana la primera passa - prou laboriosa- ha estat l'elaboració de la llista de novel-les que tracten aquest tema. Finalment, la llista ha quedat formada per quaranta títols que abracen un

\footnotetext{
${ }^{1}$ Sobre aquest tema vegeu "La novel-la històrica en la literatura juvenil catalana: una eina de recobrament nacional?" (Valriu 210: 95-100).
} 
extens període de més de trenta anys, però que es reparteixen cronològicament d'una manera molt desigual que podem esquematitzar en tres blocs: 1980-1989: 4 llibres; 19901999: 8 llibres; 2000-20011: 28 llibres.

Durant el franquisme era molt difícil poder publicar llibres juvenils que tractessin el tema de la Guerra Civil des de l'òptica dels vençuts, recordem que totes les publicacions estaven subjectes a l'aprovació de la censura. ${ }^{2}$ El 1975 morí el general Franco i s'acabà així el període de la dictadura que dóna pas a la transició cap a la democràcia. Els llibres publicats a la dècada dels 80 són només tres, dels quals únicament Guerra incivil (1981) de Manuel Tort tracta directament la guerra, els altres dos ho fan de forma tangencial. Els deu anys següents, però, només sumen vuit títols més i no és fins al final del període que es publiquen les obres més significatives i plenament centrades en la guerra, com és el cas de Silenci al cor (1999) de Jaume Cela. En canvi, entre 2000 i 2008 hem documentat 24 llibres -dels quals tres són àlbums i la resta novel-les-, una xifra realment espectacular si tenim en compte les dimensions de la cultura catalana i la nòmina d'escriptors que es dediquen a la narrativa juvenil. Podem parlar clarament d'un auge d'aquest tema no comparable a cap altra. No voldríem parlar de "tema de moda" perquè ens sembla que banalitzaríem la qüestió. Creiem que les motivacions d'aquest fenomen cal buscar-les en el batec de gran part de la societat que -finalment- començà a manifestar el seu desacord amb l'oblit imposat per la jerarquia i reclama el dret a la memòria i la revisió de tot allò que succeí en el país entre 1936-39. Com assenyala Joan Portell en referència a l'aparició tardana del tema de la guerra en la literatura juvenil catalana:

Una causa que es podria apuntar de la causa d'aquest oblit podria ser que com que els adults encara no havien estat capaços de cosir les ferides que ells mateixos van obrir, els escriptors, en tant en quant adults, no s'han vist amb cor d'explicar la Guerra Civil als infants $i$ als joves. (Portell 2008: 58)

Juntament amb aquesta reivindicació de la memòria històrica hi ha també una qüestió generacional. El escriptors que publiquen la majoria d'aquestes obres han nascut a partir dels anys cinquanta, la qual cosa significa un distanciament biogràfic amb els tres anys de guerra $\mathrm{i}$ amb la dura dècada posterior marcada per les penúries de la postguerra, encara que llur infància i adolescència s'insereixi en el període franquista. Aquest distanciament obre també la possibilitat d'una nova mirada, menys traumàtica i de l'absència de por a parlar del tema, una por ben arrelada en tots els qui visqueren la guerra en primera persona, $\mathrm{i}$ encara més en el qui ho feren en el bàndol dels vençuts.

Una altra pregunta que ens formulem és si -amb la novel·la històrica en general i amb aquestes obres en concret- els autors tenien la intenció d'omplir el buit de l'ensenyament de la història catalana a l'escola. La resposta ha de ser matisada. Algunes sèries d'obres, seqüenciades i sistemàtiques, és evident que tenen aquest propòsit. ${ }^{3}$ La majoria, però, responen més a la fascinació de l'autor per aquest període o a la voluntat d'aportar un cert testimoni i al gust de novel-lar que a una intencionalitat didàctica expressa. D'altra banda, amb la normalització dels continguts a l'escola, la història del país ha trobat el seu lloc i no

\footnotetext{
${ }^{2}$ Sobre les característiques de la literatura infantil de postguerra vegeu l'article "La actual narrativa infantil y juvenil española" (Vásquez 2003: 61-84).

${ }_{3}^{3}$ Ens referim, per exemple, a les obres d'Oriol Vergés que formen la col-lecció "Les arrels", publicada per l'Abadia de Montserrat i que novel·len tota la història de Catalunya. Ni ha tres que tracten la Guerra Civil: Amb el carnet i la pistola (1936-1939), Els cementiris sagnants de Mallorca i 1938: viure i morir sota les bombes,
} 
necessita del subterfugi de la novel·la -com succeïa a la dècada dels setanta-, tot i que la lectura d'aquestes novel-les pot ser un camí engrescador d'aprenentatge. És clar que -en conjunt- la novel-la històrica catalana té una voluntat més didàctica al llarg dels anys 60-70 quan la cultura catalana encara era prohibida a l'escola i es fa més literària, intimista, psicològica i de creixement o bé de denúncia social a les dècades 1980-2010, en sintonia amb les tendències literàries vigents i la situació de progressiva normalitat de la cultura del país.

En el cas concret que ens ocupa, la sensació que produeixen la majoria d'obres no és la de voler vehicular una lliçó d'història, sinó la voluntat de deixar un testimoni d'una barbàrie i de l'opressió i negació d'una cultura silenciada a la força.

\section{Tipologies narratives}

En aquesta trentena de novel·les trobem un ample ventall d'enfocaments narratius que els autors usen per estructurar els arguments, exposar els temes i crear els personatges ficcionals, sempre a la recerca d'una bona connexió amb el lector al qual s'adrecen, un lector jove que probablement de la Guerra Civil només en té vagues referències, idees estereotipades o prejudicis vinculats al seu entorn familiar o social. ${ }^{4}$

La forma més usual de la narrativa -el narrador en tercera persona $\mathrm{i}$ omniscient que explica els fets al lector- és la que usa Oriol Vergés a 1938: Viure i morir sota les bombes obra que forma part d'un conjunt de llibres que expliquen la història del país en una col·lecció titulada de forma significativa "Les arrels"- i també l'elegida a Contraban de Miquel Rayó, El cim dels espadats de Marcel Fité, El tresor dels maquis de Joan Constans, La cova del torrent de Pere Pons i moltes d'altres. Sovint la tria del narrador en tercera persona ve marcada per l'argument; la majoria de narracions que hem esmentat són de protagonista coral i prenen la forma externa dels coneguts llibres de colles, on un grup d'adolescents tenen com a objectiu la resolució d'algun conflicte o l'esclariment d'un misteri, mentre entre ells es forma un teixit de relacions diverses (amistat, complicitat, amor, odi, dependència, solidaritat, etc.). El narrador en tercera persona permet informar el lector de les accions i de l'itinerari vital de cada un dels components de la colla d'una manera clara i entenedora.

Una altra opció molt habitual en aquests relats és la de l'estructura que es basa en el diàleg. Una persona que ha viscut la guerra explica els seus records a una altra, generalment un adolescent amb els qual manté un lligam familiar o d'amistat, pot esser un avi o àvia que parla amb el seu nét o néta o bé un jove que ha entrat en contacte amb una persona major per altres raons. ${ }^{5}$ El motiu que desencadena aquest diàleg intergeneracional pot ser divers, però sempre es tracta d'un pont que s'estableix entre el passat i el present: la troballa d'unes cartes o un diari, ${ }^{6}$ una fotografia en un llibre ${ }^{7}$ o una exposició, una manifestació contra una guerra contemporània, una mort, etc.

\footnotetext{
${ }^{4}$ Encara que en aquest article ens centrem en les novel-les juvenils, no volem deixar de tenir en compte els llibres il·lustrats, semblants als àlbums, que tracten aquests temes però s'adrecen als infants, no al públic juvenil. Com assenyala Guida Planes: “... els àlbums il·lustrats poden ser una eina magnífica per entrar a poc a poc en la història de la Guerra Civil espanyola i per entendre'n les causes i conseqüències. Llegir -el text i les imatges- permet un espai per reflexionar ... /... els àlbums ens apropen al conflicte a través de la sensibilitat artística i emocional de tot el seu conjunt." (Planes 2011: 45).

${ }^{5}$ Vegeu Jo, el desconegut d'Antoni Dalmases, Les galetes del Saló de Te Continental de Josep Fonolleras o Els silencis de la Boca de la Mina d'Andreu Sotorra, entre d'altres.

${ }^{6}$ Vegeu Temps regirats d'Antoni Dalmases, novel·la en la qual el jove narrador aconsegueix parlar amb la seva àvia dels fets de la guerra, després de vèncer la resistència de la dona que es negava en rodó a tractar aquest tema.
} 
Altres autors desenvolupen la seva narració a partir d'un relat en primera persona que no es basa en el diàleg, sinó en la vivència contada en present, cas de Silenci al cor o El centaure, ambdós de Jaume Cela, o El camí del far de Miquel Rayó. La veu narrativa és la d'un infant o adolescent que veu amb sorpresa, incredulitat, incertesa i temor els desastres que la guerra i la postguerra infligeixen al seu món, abans plàcid i ordenat. El trasbals vital -emocional i material- és explicat al lector en primera persona, sovint des de la ingenuïtat infantil que posa de relleu l'absurd del conflicte, i provoca una immediata relació d'empatia entre el narrador infant $\mathrm{i}$ el lector:

Els nins no enteníem res de tot aquell discurs. Ignoràvem el significat de paraules com "pàtria" o "secular", i molt més encara ignoràvem quin era l'error que aquells homes havien comès.

Debades, jo li'n demanava clarícia a la mare, perquè ella només responia:

-L'error és la guerra, Miquelet. La guerra...- i voltava el cap, de sobte ennuegada.

(Rayó, 2000: 14)

Finalment, una altra estructura habitual és la que desenvolupa el relat mitjançant cartes, diaris personals o textos de memòries. La guerra explicada en cartes o notes personals escrites al llarg dels anys del conflicte, la guerra explicada en epístoles que fan memòria d'allò que succeí, els fragments de diaris personals o els textos redactats temps després per deixar testimoni de vivències personals o col·lectives que s'emmarquen en la guerra, la resistència, l'exili o la repressió de la postguerra. Així, trobem un quadern de memòries que escriu l'avi abans de morir a la novel-la Temps regirats i que obre els ulls al seu nét sobre els fets de la guerra i la ideologia dels seus avis, també la carta que l'avi Ton regala a la seva néta Alba a El cant de l'esparver per explicar-li com ell va viure aquells anys terribles a Barcelona. Però, sens dubte, la novel-la que desenvolupa de forma més acurada i complexa l'estructura epistolar és Els silencis de Derrís de Bartomeu Cruells. El llibre és un conjunt articulat de cartes que escriuen diversos personatges que d'un manera o l'altra s'impliquen en la trama. La primera està datada el 1909 -fets de la Setmana Tràgica de Barcelona- i l'última correspon a l'any 1999. Totes les cartes estan escrites en anys acabats en el número nou i aquesta seqüència temporal de deu en de anys permet a l'autor esbossar la trajectòria històrica del s. XIX a Catalunya en particular i a Espanya en general. La novel·la no té la Guerra Civil com a eix central, però si com a vector importantíssim en el devenir humà i social dels personatges. El text és ric en referències històriques, però sempre presentades des de l'òptica de la gent del carrer que pateix en la seva vida quotidiana els esdeveniments polítics que sacsegen la societat.

\section{Les coordenades de la ficció: temps i espai narratiu}

El nucli central de les novel·les que analitzem és la Guerra Civil espanyola, un conflicte que històricament s'emmarca en dues dates ben concretes: del 18 de juliol de 1936 - data de l'alçament militar- a l'1 d'abril de 1939 -dia en què Franco la donà per acabada-. És evident, però, que les novel-les no es circumscriuen a aquests tres anys de guerra oberta sinó que hi ha l'abans -les convulsions socials i polítiques de les tres primeres dècades del s. XX- i el després que arriba fins a l'actualitat, amb una especial presència dels anys més durs de la postguerra. Com assenyala Isabelle Gräfin (Gräfin 2007: 182) en aquestes novel·les es poden distingir essencialment tres espais temporals concrets:

\footnotetext{
${ }^{7}$ Vegeu igualment Temps regirats, obra en la qual una fotografia inicia el relat.
} 
a) Novel·les que se situen en el temps històric de la guerra (1936-39).

b) Novel·les que se situen en la postguerra (1940-60 aproximadament)

c) Novel·les que se situen en un temps més pròxim, els últims anys del franquisme, el període de la transició o l'actualitat.

A moltes de les novel-les analitzades apareixen un bon nombre de dates històricament rellevants que situen el lector, al costat dels esdeveniments personals dels protagonistes. D'altra banda, les estructures narratives abans esmentades -els diàlegs, les cartes, la narració des de la memòria- fa habitual la juxtaposició del temps present amb la recreació del temps passat. Així, un nombre important de novel·les comencen a l'actualitat i després es desenvolupen en els anys de la guerra i la postguerra. Aquest és el cas d'El cant de l'esparver de Joaquim Carbó, Temps regirats i Jo, el desconegut d'Antoni Dalmases, entre d'altres. A vegades la combinació dels dos temps és paritària, com passa a Les galetes del Saló de Te Continental de Josep Fonolleras on els breus capítols salten constantment de la memòria a l'actualitat. L'últim vaixell de Gemma Pascual comença i acaba el 20 de novembre de 1975, dia de la mort del dictador, en un relat d'estructura totalment tancada, però el nucli narratiu es centra en les vivències dels protagonistes durant els anys de la guerra i els primers mesos de l'exili.

Els primers anys de postguerra també tenen un paper important, d'una banda com a temps de penúries, desolació, fam, humiliació dels vençuts contrastada amb l'hegemonia dels vencedors i de l'altra pel tema de la resistència a les muntanyes o allà deçà la frontera -els maquis i els exiliats-, amb una espurna encara d'esperança que s'esvanirà en acabar la 2a Guerra Mundial amb la constatació que cap país no està disposat a qüestionar el règim de Franco.

L'espai on es desenvolupen aquestes novel·les són totes les terres de llengua catalana, com se sol dir de Fraga fins a Maó i de Salzes a Guardamar, però amb un pes específic molt important de la ciutat de Barcelona. Aquest fet és comprensible per diverses raons: el volum demogràfic i econòmic de la capital, la seva importància com a centre de decisió política, la situació geogràfica militarment estratègica -el port i la relativa proximitat a la frontera-, els important atacs aeris que va patir i -molt especialment- l'opció de la majoria de narrador que elegeixen contar les vivències de la reraguarda en comptes de les lluites $\mathrm{i}$ els enfrontaments de la primera línia de guerra. Així, el front és el gran absent d'aquestes novel·les. És un espai just al-ludit, imaginat o explicat, un llenç sobre el qual es projecten els malsons i les pors dels protagonistes, però mai no és un espai descrit directament ni concretat. Per importància i proximitat, el front de l'Ebre és el que s'esmenta d'una manera més reiterada a diverses novel-les. També els Pirineus en la seva doble dimensió de muntanya i de frontera són un espai amb una presència notable. Les muntanyes pirinenques són el refugi dels fugitius, l'amagatall dels maquis, el territori on amagar els béns que es volen salvar de la rapacitat o del sectarisme dels dos bàndols -ornaments litúrgics, llibres, joies, obres d'art- $\mathrm{i}$ també un espai de solidaritat, on malgrat les inclemències del temps $\mathrm{i}$ la duresa del territori és possible fugir de l'opressió de la ciutat i de la vigilància de l'enemic. ${ }^{8}$ Travessar els Pirineus esdevé sinònim de llibertat i salvació, però alhora sinònim també d'incertesa i d'exili. La comarca d'Els Ports, al País Valencià, acompleix una funció

\footnotetext{
${ }^{8}$ Vegeu El tresor dels maquis de Joan Constants, Els llops de la lluna roja de J. F. Delgado, L'últim vaixell de Gemma Pascual, Els silencis de Derrís de Bartomeu Cruells, Quan la llibertat s'amagava a les muntanyes d'Abel Caldera, entre d'altres.
} 
semblant pel que fa a refugi dels resistents. ${ }^{9} \mathrm{Hi}$ ha altres espais amb una presència més puntual: la vila de Santanyí -a Mallorca- i el camí que du cap al far construït pels presoners de guerra, ${ }^{10}$ la Ribagorça, ${ }^{11}$ l'illa de Menorca, ${ }^{12}$ altres poblacions catalanes, ${ }^{13}$ etc.

\section{Personatges: el valor del testimoni}

A grans trets podríem dividir l'extensa nòmina de personatges que apareixen en aquestes novel-les en dos grans grups. D'una banda, aquells que han viscut la guerra $\mathrm{i}$ l'expliquen des de la seva perspectiva de supervivents i testimonis i de l'altra els qui escolten aquest testimoni i n'extreuen un aprenentatge emocional i històric, una visió enriquidora. El primer grup és format bàsicament per gent gran que narra la seva vivència des de l'emoció i -rarament- des de la ràbia. El segon, pels joves que descobreixen una realitat fins aleshores oculta als seus ulls, però que encara és viva i bategant, atès que marca relacions, vivències, prejudicis i greuges dins l'entorn social en el qual es mouen.

Entre el primer grup hi ha homes $\mathrm{i}$ dones que han viscut i patit la guerra des d'estaments $\mathrm{i}$ oficis ben diversos: militars republicans que es converteixen en caps de la resistència a les muntanyes, obrers sindicalistes que són empresonats o abatuts per la policia, capellans perseguits, periodistes que fan de la seva tasca un testimoniatge compromès, noies abocades a la marginalitat i l'abús sexual, infermeres plenes de coratge, mestres fidels als seus principis, cacics sense escrúpols, guàrdies civils, àvies que amb la seva fermesa i el seu valor han d'assumir i resoldre situacions desesperades i un llarg etcètera. En el segon grup la majoria són adolescents que es vinculen a la memòria de la guerra per un lligam familiar o de manera fortuïta -una troballa enigmàtica, un voluntariat, un període de vacances, etc. En tots els casos, la desgana o fredor inicial envers el tema es substituït per l'interès, l'apassionament i fins i tot l'assumpció d'un rol actiu en el recobrament de la memòria històrica, sempre amb una implicació emotiva amb el personatge que ha viscut la guerra. En algunes novel·les aquest personatge mor al final del llibre, i es constata i remarca que cal deixar testimoni de les vivències de la guerra abans que la mort dels protagonistes les sumeixi en l'oblit.

$\mathrm{Cal}$ incidir en el paper fonamental dels personatges femenins -sigui quina sigui la seva edat-, tant com a motors actius de la vida a la reraguarda -la lluita per la supervivència malgrat les adversitats-, el seu paper en la resistència activa i -posteriorment- com a guardianes de la memòria d'allò que va succeir. Les dones formades en els valors de la República són presentades com a renovadores d'esquemes caducs, com la força que havia de fer possible una societat més moderna i justa. Són obreres, mestres, infermeres o pageses que veuen els seus projectes de vida truncats per la guerra però que no per això es donen per vençudes i aporten una lliçó de vida. També tenen un rol sovint positiu els mestres fidels a la República, compromesos amb la llengua i la cultura malgrat les adversitat, persones plenament conscients que l'educació és l'única via de progrés de les societats. ${ }^{14}$

\footnotetext{
${ }^{9}$ Vegeu El tresor dels maquis de Joan Constants, Els llops de la lluna roja de J. F. Delgado, L'últim vaixell de Gemma Pascual, Els silencis de Derrís de Bartomeu Cruells, Quan la llibertat s'amagava a les muntanyes d'Abel Caldera, entre d'altres.

${ }^{10}$ El cami del far de Miquel Rayó.

${ }^{11}$ Caminar sobre gel de Manuel Valls.

${ }^{12}$ La cova del torrent de Pere Pons.

${ }^{13}$ Per exemple, Reus sota el nom fictici d'Orlanda a Els silencis de la Boca de la Mina d'Andreu Sotorra.

${ }^{14}$ Entre els diversos mestres que apareixen en aquestes novel·les, podem destacar Ramon, l'insubornable mestre de Silencia al cor de Jaume Cela.
} 
Destaquen també els metges disposats a arriscar la seva vida per guarir els ferits i els obrers disposats a lluitar per les reivindicacions del proletariat.

Les novel·les se centren en la trajectòria vital dels protagonistes, que sempre són personatges positius. En canvi, els personatges negatius que actuen com a antagonistes tenen una presència secundària $i$ en molts de casos episòdica. A nivell literari estan menys desenvolupats i resulten més plans. En alguns llibres no s'individualitzen, sinó que són un enemic ideològic difús, sense concreció.

Una figura a comentar especialment és la del maquis o guerriller antifranquista. Els maquis foren els qui -emboscats a les muntanyes- es resistiren a acceptar la victòria dels "nacionals" i dugueren a terme actes d'agitació ideològica i de sabotatge. Aquest perfil de personatge sovint és presentat a la literatura com l'arquetip del rebel -d'igual manera que el pirata o el bandoler- i voltat d'una certa aura mítica. Els maquis actuaren bàsicament entre 1939 i 1947, encara que els últims documentats visqueren fins a principis dels anys seixanta. Foren perseguits sense pietat i per això la majoria moriren abatuts o foren detinguts i empresonats i altres s'exiliaren a França o Marroc. Antoni Dalmases tracta el tema dels maquis a la seva novel-la breu Temps regirats: Albert, un jove estudiant de secundària, descobreix amb estupor que el seu avi -i també la seva àvia- col-laboraren activament amb el moviment antifranquista i realitzaren accions d'espionatge i sabotatge de guerrilla urbana- a Barcelona juntament amb dos maquis històricament ben documentats (Francesc Sabaté Llompart el Quico (1915-1960) i Josep Lluís Facerías (1920-1957). Encara que la novel-la destil·la una certa admiració cap als maquis i els seus esforços des de la resistència per la seva fidelitat a un ideal, no podem dir que el relat doni un tractament mític o heroic als personatges, sinó que l'autor els presenta amb llums i ombres, amb les seves pors i petites misèries, amb un volum i uns clarobscurs que els fa més humans. També es centra en el tema dels maquis la novel-la titulada Quan la llibertat s'amagava a les muntanyes, un títol prou significatiu de l'escriptor Abel Caldera.

\section{Ideologia i literatura: del blanc i el negre a la simfonia de grisos}

Habitualment, i a tot arreu, la novel-la històrica ha estat marcada per una considerable càrrega ideològica. De tots els gèneres de la literatura juvenil potser aquest és el que permet més fàcilment la manipulació i l'afany d'adoctrinament, tal com ho demostren la majoria de novel·les històriques publicades sota règims dictatorials. Quin ús ideològic fan els autors catalans d'aquest tipus de literatura? La resposta a aquesta pregunta requereix un estudi més exhaustiu que aquest, una anàlisi detallada. No obstant, podem dir que és innegable que les novel·les que comentem pretenen crear uns referents històrics que tipifiquin unes aspiracions comunes encaminades a fer país, a construir el sentiment de pertinença $\mathrm{i}$ d'identitat nacional del lector. Però també ho és que ho fan sense sectarismes i amb un tarannà obert, integrador i respectuós, defugint generalment el tractament maniqueu dels temes. És ben clar que a través d'aquestes obres hom pretén transmetre valors morals, cívics i patriòtics, per aquest ordre. El denominador comú de la majoria de les obres és la defensa de la llibertat, tant la dels individus com la dels pobles. I per aconseguir-la, els autors posen l'accent en el valor del diàleg, l'enteniment i la bona voluntat més que en la força de les armes o la repressió. Per exemple, en els temes bèl-lics són llibres que s'allunyen volgudament de la descripció dels aspectes més crus (batalles, assassinats, etc.) i per això com ja hem comentat- elegeixen sovint escenaris de reraguarda, que permeten mostrar al lector com sovint són els més dèbils i innocents els qui han de patir les conseqüències de les actituds intolerants o violentes dels poderosos. Aquesta tria també és fa palesa en el tipus de protagonistes, que no són herois de caràcter èpic, sinó més tost personatges senzills 
però intel-ligents $i$ assenyats $i$-sobretot- fidels als seus ideals que es veuen immersos en un context d'enfrontament que els empeny a haver d'actuar, prendre partit i responsabilitats. Com encertadament assenyala Xabier Etxaniz: "La situación de violencia es un elemento más del contexto realista de la novela iniciàtica." (Etxaniz 2004: 91).

En la trentena de novel-les que comentem hi ha una sèrie d'elements que conformen una mena de "denominador comú" referencial compartit i remarcat per tots als autors i que podríem esquematitzar així:

- Legitimitat vs il·legitimitat: la legalitat de la República front a la il·legalitat de l'alçament militar.

-Democràcia $v s$ dictadura: la República es sustenta en la democràcia i el règim franquista en el feixisme i el totalitarisme.

-Pluralitat nacional vs espanyolisme: la República respecta la diversitat nacional espanyola i el franquisme l'aniquila (en tots els aspectes: llengua, cultura i dret).

-Llibertat religiosa $v s$ nacionalcatolicisme: front al laïcisme republicà el catolicisme imposat del franquisme.

-Feminisme vs masclisme: la República treballa per a l'emancipació femenina, el franquisme reclou la dona en tasques domèstiques i assistencials i retalla els seus drets com a persona.

-Educació vs incultura: una de les prioritats republicanes és l'educació de la població, el franquisme veu en l'educació dels ciutadans un perill, per això en comptes d'educar adoctrina.

D'aquesta esquema en podem deduir els principals temes i motius que desenvolupen les novel·les i també llur ideologia subjacent i el tractament que fan de les identitats. La posició ideològica dels autors - que traspua de manera més o menys evident dels diversos elements que conformen el relats que comentem- és força homogènia i la podem sintetitzar en una mena de retrat-robot format per cinc adjectius: republicana, catalanista, feminista, antibel-licista i d'esquerres. Els autors escriuen en una clara posició a favor de la república, la cultura catalana, els drets de les dones, el rebuig a la guerra i els posicionament ideològics progressistes. És, doncs, un rebuig total a la ideologia propugnada pel franquisme d'exalçament de la dictadura, d'opressió de les cultures i llengües diferents de la castellana, de masclisme, d'identificació de la guerra amb una croada o causa santa i amb plantejaments ideològics immobilistes. Val a dir que -atès el posicionament ideològic dels autors- és comprensible que aquestes obres no es publiquin fins vint anys després de la fi de la dictadura, perquè la transició del país cap a la democràcia i el reconeixement de les nacionalitats ha estat un camí lent i no exempt d'entrebancs. De fet, la revisió històrica de la guerra a l'estat espanyol és encara un procés obert i ple de dificultats, un conflicte viu diàriament $-n$ 'hi ha prou de llegir els diaris- marcat per lleis que arriben tard, sentències judicials contradictòries, desqualificacions de jutges, problemes per obrir fosses comunes $\mathrm{i}$ exhumar cadàvers de persones assassinades durant la guerra, arxius segrestats o tancats i barrats a la consulta pública, documents desapareguts i veus silenciades.

\section{Escriptors i escriptores: a la recerca del testimoniatge i la memòria}

Pel que fa als autors que novel·len el tema de la Guerra Civil, podem dir que conformen una nòmina diversa $\mathrm{i}$ variada, tant pels estils, el to narratiu o les preferències a l'hora d'elegir escenaris i arguments. Si haguéssim de buscar un element comú, aquest seria el bon nivell i l'acurada documentació que -generalment- traspuen les recreacions de l'època i els ambients. Val a dir, també, que en general no són autors d'un únic gènere, sinó que a 
més de novel·les històriques escriuen en altres coordenades. Un cop d'ull a les dates de naixença dels autors de les obres estudiades ens pot portar a algunes reflexions significatives.

Nascuts entre 1920 i 1940: Francesc Grau i Viader, Manuel Tort, Joaquim Carbó, Oriol Vergés, Joan Constans, Sebastià Sorribas, Ricard Creus, Emili Teixidor.

Nascuts entre 1941 i 1960: Pere Morey, Pere Pons, Bartomeu Cruells, Andreu Sotorra, Antoni Dalmases, Jordi Sierra i Fabra, Jaume Cela, Joaquim Pastor, Joaquim Soler, Josep M. Fonalleras, Josep-Francesc Delgado, Miquel Rayó, Manuel Valls, Marcel Fité, Abel Caldera, Andreu Martín i Maria Barbal.

Nascuts després de 1960: Anna Cabeza, Lolita Bosch, Gemma Pascual, Pau Joan Hernàndez, Mariano Casas, Mercè Anguera, Albert Carabén, Antoni Garcia-Llorca, Albert Roca, Joaquin Biendicho, Albert Roca Orta, Joan Portell, Laia Altarriba.

Com podem veure, en el primer grup hi ha els escriptors que visqueren directament la guerra $\mathrm{i}$ els anys més durs de la postguerra $\mathrm{i}$-curiosament- és un grup de només vuit autors. Quatre d'ells són autors plenament consolidats i amb una extensa obra de novel·la juvenil catalana (Carbó, Vergés, Teixidor i Sorribas). Vergés escriu tres llibres sobre el conflicte, però inserits en una col·lecció en la qual pesa més el contingut didàctic $\mathrm{i}$ informatiu que no el pròpiament literari. Carbó, Teixidor, Creus i Sorribas aporten una obra cada un, però són tardanes i poc significatives en el conjunt de la seva obra. Constans, Grau i Tort, per la seva banda, són autors incidentals que escriuen des de la memòria i la vivència, amb la voluntat de deixar testimoni d'una guerra viscuda.

Els autors que neixen en plena època franquista són els que més han novel·lat el conflicte bèl-lic. Ells són els fills i els néts dels combatents i dels represaliats, ells són els joves que cresqueren en una dictadura opressiva i combativa amb la cultura catalana. Ells són els qui d'alguna manera mitifiquen l'època de la República i es dolen pel país que hagués pogut ser i que s'estroncà per la guerra i la dictadura. La seva guerra és una guerra apresa en els relats dels majors, en els llibres i en els senyals que ha deixat en el patrimoni. Però si no varen viure directament la guerra, sí que visqueren les seves conseqüències, sobretot en el camp de la imposició del nacionalcatolicisme, l'educació repressiva i la persecució cultural. Són els joves de la revolta del 68, de les manifestacions i les corregudes perseguits pels grisos, de la militància clandestina en partits d'esquerra, els que es rebel·laren contra el silenci imposat i la por dels vençuts. En aquest grup només hi trobem una dona, Maria Barbal, amb una obra emblemàtica (Pedra de tartera) que retrata magistralment la vivència d'una dona -aliena a qualsevol ideologia política- que pateix en carn viva els estralls de la guerra.

En el grup més jove, educats a les acaballes del franquisme i en els primer anys de la transició, no trobem canvis essencials de plantejaments ideològics respecte al grup anterior però sí que és notable la presència de veus femenines. Cinc escriptores (Anguera, Pascual, Bosch, Cabeza i Altarriba) aporten la seva visió a la novel-lització del conflicte i, en part, remarquen encara més el paper cabdal de la dona en la guerra i la postguerra.

Cada escriptor desenvolupa el seu relat d'acord amb el seu estil narratiu i la trajectòria literària pròpia. Cada autor és una veu personal que s'expressa de forma individual, però tots tenen com a objectius prioritaris el procés d'identificació i d'empatia del lector jove amb la peripècia narrada i la claredat en l'exposició dels fets històrics que són explicats o que funcionen com a teló de fons. A vegades, s'estableix un contrast volgudament remarcat en el registre lingüístic usat. La llengua col-loquial de l'interlocutor jove és plena de 
paraules pròpies de l'argot juvenil i contrasta amb l'expressió més pausada i neutra dels majors, o fins i tot amb la inclusió de termes avui totalment en desús i que designen fets o elements propis d'aquella època.

\title{
7. Més enllà de les paraules: els elements paratextuals
}

La narració de la Guerra Civil en la literatura catalana s'ha vehiculat bàsicament mitjançant la novel·la juvenil adreçada a lectors de més de catorze anys. Això és fa palès no només en els textos sinó en les colleccions on les editorials els publiquen, que són clarament destinades a questa franja d'edat ("Gran Angular" de Cruïlla, "El corsari" de La Galera, "Voramar" d'Alfaguara, "L'Odissea" d'Empúries, etc.). És significatiu l'ús que es fa de les fotografies en el disseny de les cobertes dels llibres. És habitual que siguin fotografies en blanc i negre que corresponen a l'època novel-lada. Fins i tot el cas de Temps regirats de Dalmases, la fotografia té un paper fonamental en el desenvolupament de l'obra i és un dels elements centrals entorn del qual gira la història, concretament es tracta d'una fotografia de Quico Sabater, un dels últims i més cèlebres maquis catalans, fotografiat quan caminava d'incògnit pels carrers de Barcelona, en plena postguerra:

\begin{abstract}
De fet, era un retrat que no tenia res d'extraordinari: tres homes caminant per un carrer de Barcelona, amb un tramvia al fons i un edifici alt amb un anunci que no es llegia de què era. Un dels homes, el del mig, amb ulleres, duia barret, abric i bufanda. El de l'esquerra, més a prop de lña càmera, anava amb corbata $\mathrm{i}$ americana, tenia un rostre sorrut, de faccions dures que el bigoti accentuava, $\mathrm{i}$ els moviments enèrgics de qui camina amb seguretat. A la dreta, un noi que semblava més jove, amb l'abric voleiant-li una mica, duia un paquet a la mà $\mathrm{i}$ mirava fix al fotògraf, amb un gest de mitja complicitat. I va ser aquest noi, el qui em va cridar l'atenció, sobretot després de llegir el peu que deia: "Francesc Sabaté retratat per un amic a un carrer de Barcelona, probablement a l'hivern de 1946. Li agradava fer-se fotografies dins de Catalunya, on tota la policia li seguia les petjades.". El Sabaté, el que estava en primer pla, era el del bigoti, però a mi el que em tenia intrigat era el noi jove de la dreta. (Dalmases 2002: p. 8-9)
\end{abstract}

Hi ha, però, algunes poques obres aptes per a lectors més petits, a partir de deu anys. Són obres més breus, d'argument més senzill i que majoritàriament compten amb el suport de la il-lustració per fer-les més atractives visualment, tant a la coberta com a l'interior. És el cas El Moro, les taronges i la guerra de Ricard Creus, Les galetes del Saló de Te Continental de J. M. Fonalleras, El camí del far de Miquel Rayó i alguna altra, totes elles publicades en col·leccions que s'adrecen a la franja d'edat esmentada.

Finalment, ens trobem amb el cas singular i innovador de tres llibres en format d'àlbum que conformen els tres primers -i per ara únics- títols d'una col·lecció titulada precisament "La guerra dels grans". Són llibres on la il-lustració té tant de pes com el text, que està inspirat en històries reals explicades per homes i dones que varen viure la guerra. Plens de sensibilitat i amb unes il-lustracions amb tons grisos o ocres amb algunes pinzellades de vermell, són una proposta apta per apropar el tema de guerra als lectors més joves, però interessant també com a opció de lectura a qualsevol edat, atès que il·lustració $\mathrm{i}$ text es potencien per multiplicar l'impacte del missatge que vehiculen.

Un altre aspecte a tenir en compte és el dels premis atorgats. Un nombre considerable d'aquestes obres han rebut diversos premis, en convocatòries adreçades a textos inèdits o en guardons que reconeixen la vàlua de llibres ja publicats. Aquest és un bon indicador de l'interès que susciten aquestes obres, de la seva recepció positiva tant per part de la crítica 
com dels mediadors. ${ }^{15}$ No tenim dades que ens indiquin el seu èxit entre els lectors, però l'aposta de les editorials per aquest tema des de la dècada dels noranta $\mathrm{i}$ els primers deu anys del s. XXI ens fa pensar que és un tema que interessa els lectors.

\section{Conclusions per a un tema encara obert}

Un cop feta la revisió de les diverses obres del corpus que hem pres com a referència sobre el tema de la Guerra Civil, podem remarcar alguns punts que ens ajuden a sintetitzar l'anàlisi realitzada:

1. Els autors novel-len sempre des del punt de vista dels perdedors, però, com escriu Gemma Pascual a L'últim vaixell: "ens han vençut, però no ens han derrotat". És a dir, tots aquells que perderen la guerra no renunciaren als seus ideals ni a les seves conviccions.

2. És significativa l'absència de novel-les juvenils en català que tractin sobre la Guerra Civil al llarg dels pràcticament cinquanta anys posteriors al conflicte (1940-1980) i contrasta amb la publicació de més de quaranta llibres en les dècades següents (1981-2010), especialment a partir dels anys noranta del s. XX. Aquest fet s'explica per la llarguíssima postguerra marcada per la fèrria dictadura, les fondes ferides emocionals dels qui patiren la guerra en carn pròpia i la manca d'una reivindicació social de la memòria històrica fins a la dècada dels noranta. Quan la societat comença a reclamar la dignificació dels vençuts, els escriptors comencen a publicar obres sobre el conflicte.

3. Les novel·les analitzades tracten el tema sense afany didàctic però amb una decidida voluntat d'informar, d'assabentar els joves lectors sobre allò que succeí. Posen l'accent en els drames personals i en la pèrdua social i cultural que patí el país, però no en l'alliçonament sobre fets i personatges històrics.

4. Les tipologies narratives usades són diverses, però hi ha un ús notable de tècniques narratives vinculades a la memòria: cartes, documents, relats de fets succeïts, pàgines de diaris personals, textos de memòries, diàlegs entre persones majors i joves, etc.

5. El temps dels relats sovint s'inicia en el present i després es retrotreu al passat històric, mitjançant el record o la narració d'experiències viscudes. Els anys més novel·lats són els tres de la guerra i els primers de la postguerra. L'espai més tractat és Barcelona i en segon lloc els Pirineus, presentat com el camí de l'exili o el lloc de refugi. El front, amb poques excepcions, és el gran absent d'aquestes narracions.

6. Els personatges essencials són els supervivents, protagonistes i testimonis dels horrors de la guerra. Ells expliquen no sols la seva història sinó també la dels companys que moriren a la guerra o els que s'integraren en els maquis. El contrapunt necessari són els joves que s'interessen per conèixer la seva peripècia (estudiants, advocats, familiars, periodistes, voluntaris, etc.) i que possibiliten la narració, sovint catàrtica, dels fets; uns i altres estan tractats en positiu. El paper destacat el tenen les dones, com a persones que patiren la guerra encara que no anessin directament al front $\mathrm{i}$ com a guardianes de la memòria.

\footnotetext{
${ }^{15}$ Alguns dels premis rebuts per aquestes obres són: Premi Gran Angular 1999 de narrativa juvenil a Els silencis de Derrís, premi Abril 1999 a Silenci al cor, premi Crítica Serra d’Or del 1999 i premi de la Institució de les Lletres Catalanes de narrativa juvenil del 2000 a L'ombra del Stuka, premi Edebé de l'any 2000 a El camí del far, premi Ramon Muntaner 2002 a Els llops de la lluna roja, premi Samaruc 2005 a L'últim vaixell, premi Vaixell de Vapor 2007 a Les galetes del Saló de Te Continental, IX Premi Llibreter 2008 a Fill de rojo.
} 
7. La posició ideològica des de la qual són escrites les novel·les és força homogènia, de caràcter progressista i catalanista. En general, els autors projecten una visió molt positiva - a voltes idealitzada- del període de la República que contrasta amb la dictadura posterior, marcada per la repressió social i religiosa i l'anticatalanisme.

8. Els autors que més tracten aquest tema són no els que visqueren directament el conflicte sinó el que varen néixer en el període franquista i foren educats en les coordenades del nacionalcatolicisme, una època en la qual els vençuts de la guerra eren silenciats i oblidats.

9. Tant pels elements textuals com paratextuals, aquestes obres s'adrecen als lectors joves, tot i que moltes són també atractives per als adults. Hi, també, alguns àlbums i diverses narracions per a pre-adolescents, que apropen el tema als més joves.

L'anàlisi realitzada ens porta a concloure que aquests últims vint anys la literatura juvenil catalana ha encarat amb força, empenta i decisió un tema fins aleshores considerat tabú: la Guerra Civil espanyola i les seves terribles conseqüències sobre la població i la cultura catalana. La collita ha estat variada, abundosa $\mathrm{i}$ amb algunes obres de qualitat més que notable. Escriure sobre la guerra, parlar-ne, recordar-la, reivindicar-ne la memòria s'ha dibuixat com un camí de catarsi i de superació, la guerra explicada als joves per tal de no repetir els errors que la feren possible, ni en el nostre país ni en cap altre lloc del món.

\section{Referències bibliogràfiques}

ETXANIZ ERLE, Xabier (2004): "La ideología en la literatura infantil y juvenil”. Cauce, Revista de Filología y su Didàctica 27: 83-96.

FAULÍ, Josep (1999): Novel·la catalana i guerra civil. Barcelona: Publicacions de l'Abadia de Montserrat.

GRÄFIM DEYM, Isabelle (2007): "La memoria de la Guerra Civil española en la literatura infantil y juvenil”. Studia historica. Historia contemporánea 25:181-190.

PLANES FERRER, Guida (2011): "La narració de la Guerra Civil espanyola en els àlbums il·lustrats". Bellaterra Journal of Theaching \& Learning Language \& Literature vol. 4 (4): 32-47

PORTELL, Joan (2001): "Històries de la Guerra Incivil". Faristol. Revista del Consell Català del Llibre per a Infants 40: 15-18.

ROIG-RECHOU, Blanca (Ed.) (2008): A Guerra Civil Española na narrativa infantil e xuvenil. Vigo: Edicións Xerais de Galicia.

SERVEI DE DOCUMENTACIÓ DE LITERATURA INFANTIL I JUVENIL (Biblioteca Xavier Benguerel) (2008): Il·lustrar i escriure la Guerra Civil. Guia de lectura. Barcelona.

VÁSQUEZ, Magdalena (2003): "La actual narrativa infantil y juvenil española". Revista de Filología, Lingüística y Literatura vol. 29 (1) 


\section{ANNEX 1: Obres analitzades}

Altarriba, Laia (2008): El barret del milicià, il·lustracions Guillem Cifré, Barcelona, Tantàgora.

Anguera, Mercè (2005): La història d'en Robert, Barcelona, La Galera.

Barbal, Maria (1985): Pedra de tartera, Barcelona, Laia.

Biendicho, Joaquin (2009): 1937, Barcelona: Edicions Proa.

Bosch, Lolita (2006): Negra nit, Barcelona: Editorial Columna.

Cabeza, Anna (2010): Un dia sencer de blat, Barcelona: Editorial Bambú.

Carbó, Joaquim (1997), El cant de l'esparver, il·lustracions José M. Lavarello, Barcelona: Cruïlla,

Caldera i Pujols, Abel (2004): Quan la llibertat s'amagava a les muntanyes, Alzira:

Bromera.

Carabén, Armand (2008): El diari de la Queta Canals. Barcelona: Empúries.

Casas, Mariano (2001), Escales d'una fuga, Alzira: Bromera..

Cela, Jaume (1999), Silenci al cor, Barcelona: Editors Associats/La Galera.

Cela, Jaume (2004): El centaure, Barcelona: La Galera.

Cela, Jaume (2007): El temps que ens toca viure, il-lustracions Javier Andrada. Barcelona: Cruïlla.

Creus, Ricard (1984): El Moro, les taronges i la guerra, il·lustracions Lluïsa Jover Barcelona: Argos Vergara.

Cruells, Bartomeu (2000): Els silencis de Derrís, Barcelona: Cruïlla

Constans i Aubert, Joan (2005): El tresor dels maquis, Barcelona: Barcanova.

Dalmases, Antoni (2002): Temps regirats, Barcelona: Cruïlla.

Dalmases, Antoni (2005): Jo, el desconegut, Barcelona: Cruïlla.

Delgado, J. Francesc (2002): Els llops de la lluna roja, Barcelona: Empúries

Fité, Marcel (2008): Els cims dels espadats, Barcelona: Barcanova.

Fonalleras, Josep M. (2007): Les galetes del saló de te continental, Barcelona: Cruïlla.

Garcia Llorca, Antoni (2003): El rei dels senglars, il·lustracions Tha, Barcelona:

Cruilla.

Grau i Viader, Francesc (1978): Dues línies terriblement paral·leles, Barcelona: Pòrtic.

Hernàndez, Pau Joan (1998): L'ombra del Stuka, Barcelona: Empúries.

Martín, Andreu (2000): Veritats a mitges, Barcelona: Empúries.

Morey, Pere (1992): ;Mai no moriràs, Gilgamesh!, Barcelona: Cruïlla.

Pasqual, Gemma (2003): L'últim vaixell, Picanya: Alfaguara-Voramar.

Pastor, Joaquim (2011): El cant de la mallerenga, Barcelona: Editorial Bambú.

Pons, Pere (2005): La cova del torrent, il-lustracions Pablo Auladell, Barcelona: Cruïlla. Portell, Joan (2007): Fill de rojo, il·lustracions Ignasi Blanch, Barcelona: Tantàgora.

Rayó i Ferrer, Miquel (1995): Contraban, Barcelona: Cruïlla.

Rayó i Ferrer, Miquel (2000): El camí del far, il·lustracions Mercè Arànega, Barcelona:

Edebé.

Roca Orta, Albert (1998): Un cargol per a l'Emma, il·lustracions Gemma Sales. Barcelona: Edebé.

Ros, Roser (2007), Els tres tambors, il·lustracions Sílvia Cabestany, Barcelona: Tantàgora.

Sierra i Fabra, Jordi (2000): Adormits sobre els miralls, Barcelona: La Galera -

Tàndem.

Sierra i Fabra, Jordi (2010): Set dies de juliol, Barcelona: Plaza y Janés. 
Soler, Joaquim (1981): El fantasma del Fluvià, Barcelona: Edicions de La Magrana. Sorribas, Sebastià (2007): Prop del llac, Barcelona: Baula.

Sotorra, Andreu (2007): Els silencis de la boca de la mina, Barcelona: Cruïlla.

Teixidor, Emili (1986): En Ranquet $i$ el tresor, il·lustracions Francesc Infante, Barcelona: Cruïlla.

Tort i Martí, Manuel (1981), Guerra incivil, Barcelona: Claret.

Valls, Manel (2003): Caminar sobre gel, Barcelona: Columna.

Vergés, Oriol (1996), Amb el carnet i la pistola, Barcelona: Publicacions de l'Abadia de Montserrat, col. Les Arrels.

Vergés, Oriol (1996), Els cementiris sagnants de Mallorca, Barcelona: Publicacions de l'Abadia de Montserrat, col. Les Arrels.

Vergés, Oriol (1998), 1938, viure i morir sota les bombes, Barcelona: Publicacions de l'Abadia de Montserrat, col. Les Arrels.

$\begin{array}{llll}\text { ANNEX 2: Cronologia } & & \\ & & & \\ 1978 & \text { Dues linies terriblement pa- } & 2003 & \text { El rei dels senglars } \\ \text { ral-leles } & 2003 & \text { L'últim vaixell } \\ 1981 & \text { Guerra incivil } & 2003 & \text { Caminar sobre gel } \\ 1981 & \text { El fantasma del Fluvià } & 2004 & \text { El centaure } \\ 1984 & \text { El Moro, les taronges } \text { i la guerra } & 2004 & \text { Quan la llibertat s'amagava a les } \\ 1985 & \text { Pedra de tartera } & & \text { muntanyes } \\ 1986 & \text { En Ranquet } \text { i el tresor } & 2005 & \text { El tresor dels maquis } \\ 1992 & \text { iMai no moriràs, Gilgamesh! } & 2005 & \text { Jo,el desconegut } \\ 1995 & \text { Contraban } & 2005 & \text { La cova del torrent } \\ 1996 & \text { Amb el carnet i la pistola: } 1936- & 2006 & \text { Negra nit } \\ & \text { 1939 } & 2007 & \text { Les galetes del Saló de Te Conti- } \\ 1996 & \text { Els cementiris sagnants de Ma- } & & \text { nental } \\ & \text { llorca } & 2007 & \text { El temps que ens toca viure } \\ 1997 & \text { El cant de l'esparver } & 2007 & \text { Els silencis de la Boca de la } \\ 1998 & \text { 1938: Viure i morir sota les } & \text { Mina } & \\ & \text { bombes } & 2007 & \text { Fill de rojo } \\ 1998 & \text { L'ombra de l'Stuka } & 2007 & \text { Els tres tambors } \\ 1999 & \text { Silenci al cor } & 2007 & \text { Prop del llac } \\ 2000 & \text { Els silencis de Derrís } & 2008 & \text { El barret del milicià } \\ 2000 & \text { Veritats a mitges } & 2008 & \text { El cim dels espadats } \\ 2000 & \text { Adormits sobre els miralls } & 2008 & \text { El diari de la Queta Canals } \\ 2001 & \text { El cami del far } & 2008 & \text { 1937 } \\ 2001 & \text { Escales d'una fuga } & 2010 & \text { Un dia sencer de blat } \\ 2002 & \text { Els llops de la lluna roja } & 2010 & \text { Set dies de juliol } \\ 2002 & \text { Temps regirats } & 2011 & \text { El cant de la mallerenga } \\ & & \end{array}$

